\title{
Research on the Construction of the Contingent of Cadres in Colleges and Universities Based on the Idea of "the Unity of Knowledge and Action"
}

\author{
Lijuan Chang \\ School of Marxism, Xi'an University, 710065
}

Keywords: "The unity of knowledge and action"; Colleges and universities; Cadres

\begin{abstract}
Along with the economic and social development, China's demand for talents presents a blowout state. This demand is not only embodied in quantity, but also in the requirements for quality. As the forward position of talent training, colleges and universities play an irreplaceable role in it. The construction of the contingent of cadres in colleges and universities is the core issue of the whole construction of colleges and universities in the new historical period. Integrating the idea of "the unity of knowledge and action" into the construction of the contingent of cadres in colleges and universities is not merely the teaching requirement of university education under specific historical conditions, but the development trend of the construction of the contingent of cadres.

The cause of higher education exerts a profound impact on the long-term development of any country. After years of development, China's cause of higher education has made remarkable achievements both in the quantity and quality of running schools. The development of China's higher educational cause is not only closely related to the hard work of the vast majority of educators, but inseparably associated with national policies. In the meanwhile, it has a direct relationship with our attention to the construction of the contingent of cadres in colleges and universities.

It is a powerful organizational guarantee to promote the development of higher education in China by cultivating and shaping a contingent of cadres in colleges and universities that can stand the test, maintain a strong cohesion and combat effectiveness in any case and be able to adapt to the needs of practical work, is good at innovation in theory and full of vitality and determination in practice.

"Unify knowledge and action" was first proposed by Wang Yangming, a famous thinker in China's Ming Dynasty. The core of "the unity of knowledge and action" is to guide practice with a scientific knowledge system, achieve the combination of knowledge and action, promote action with knowledge and practice knowledge with action, inspect and enrich knowledge in practice and constrain and regulate practice with knowledge. The knowledge practice view of"the unity of knowledge and action" has a particularly important guidance value for the construction of the contingent of cadres in colleges and universities.
\end{abstract}

\section{The Scientific Connotation of "the Unity of Knowledge and Action"}

In the philosophical perspective of Chinese people, there is an inseparable relationship between action and knowledge. The two are a whole and indispensable. Action contains the purpose of human activities while knowledge refers to the conscience. "Unify knowledge and action" is a process in which the object conforms to the subject, and it refers to the unity of human's conscience and practice. The two are not mutually annexed rather than mutually linked with smooth transition. Understand the truth of things and then apply it in reality, and this truth is inseparable from reality. It is the unified thought of epistemology and practice in ancient Chinese philosophy, and it is the ultimate perfection about moral cultivation and moral practice. Ancient Chinese philosophers believed that it is not only necessary to understand "knowledge", especially practice "action", only by unifying "knowledge" and "action" together does it deserve to be called ultimate "perfection". In terms of the extension of innate knowledge ,"the unity of knowledge and action" lies the core of Yang Ming culture. First it is the extension of innate knowledge, followed by "the unity of 
knowledge and action".

\section{"Unify Knowledge and Action" in the Construction of the Contingent of Cadres in Colleges and Universities}

\section{"Unify Knowledge and Action", be Diligent in Learning and Action}

Colleges and universities are the fertile soil for human civilization, knowledge, values and ideas to inherit. In addition to the connotations of ideological and moral and educational ideas, the "knowledge" of university cadres should also have a higher level of comprehensive knowledge. With the advancement of the times, colleges and universities are always at the forefront of feeling the impact of all kinds of changes and various thoughts, therefore the knowledge level and judgment ability of university cadres should conform to the changing times and strive to keep abreast of the times. University cadres should put in time and energy to read widely and memorize clearly, and make great efforts to maintain their own comprehensive knowledge and action capability at a high level. The national organization and work conference has put forward high requirements for the ability and quality of university cadres, while university cadres must strengthen their convictions and stick to the dreams, exert themselves to be diligent in learning and action with the development of times, and bring into correspondence with the specific requirements of education and teaching under the new historical conditions.

\section{"Unify Knowledge and Action", be Virtuous and Learned}

Morality plays an decisive role in the value cognition system of China. People often say that it is necessary to strengthen morality before learning to be a decent person. University cadres face a relatively special group, and they are all the youthful students whose World outlook, outlook on life and values are taking shape. The quality of teachers' ethics among the contingent of cadres in colleges and universities will directly affect the shaping of young students' moral character and the establishment of their cognition view. From this point of view, morality is at the core of the construction of the contingent of cadres in colleges and universities. Under the general background of economic and social development, the connection between colleges and universities and society is getting closer and closer, and they are no longer ivory towers independent of the turmoil of the world. It cannot be denied that university cadres will face a variety of temptations or confusions from time to time, and if breaking away from the constraints of teacher's ethics and moral norms, our university teachers may easily deviate from their own original intentions for occupations driven by the temptation of interest. Especially, university cadres should have an overall awareness, and be good at considering gains and losses in the long run. In the decision-making of major issues, they should broaden their horizons, and deal with problems and solve problems from the development of education and teaching, the requirements of job responsibilities and students' ability training. Action and knowledge are the extensions of teachers' ethics from a certain point of view, and university cadres with a good moral consciousness will inevitably take scientific research, long-term construction of talents, serving the society and cultural inheritance as the starting point and ending point of all their work.

\section{"Unify Knowledge and Action", Educate People with Affection}

Bai Juyi, a poet in the Tang Dynasty, said: "nothing touches the heart more than true feelings". This sentence tells the true meaning of affective education, and the word of affection runs through the work of university cadres. We love our own work and care about our own students. One of the key but easily ignored problems in the construction of the contingent of cadres in colleges and universities is educating people with affection. In"the unity of knowledge and action", we advocate to regard the idea as the forerunner of action. In respect of education and teaching thoughts, we must try every means to make the vast majority of cadres moved to some extent at the spiritual level, really understand the importance of the occupations they are engaged in and then enhance their consciousness of service, maintain a high enthusiasm in work, study and life, and follow their own hearts and maintain internal and external unity; conduct extensive communications with teachers and students in education and teaching, think about what they think, be eager to meet the needs of others, and try hard to do well in their own jobs relying on the post; in work, it is necessary to be 
good at giving play to the role of affective factors and pay attention to help students to change by education and persuasion. From the perspective of educational psychology, the process of education is primarily the process of mutual satisfaction between educator and educatee. We must attach importance to the subconscious education role of affective factors and teach through invisible education.

\section{"Unify Knowledge and Action", Lay Stress on Practice}

The viewpoint of "the unity of knowledge and action" attaches great importance to the role of practice. Human's view of knowledge and action is affected by history and time because practice always keeps developing and evolving. In the continuous practice, people realize that action and knowledge are a whole that are mutually dependent and cannot be separated. In action, people tend to follow their inner inspirations and follow the guidance to the cognition of things. In action, people constantly summarize and enhance the gains and losses in practice so as to achieve a new understanding of things. In the construction of the contingent of cadres in colleges and universities, we lay stress on practice based on two points: first of all, from the management level, the development of our management measures should be in line with the school's educational philosophy, but fully consider the actual conditions of teachers and teachers rather than act recklessly in a fixed and unchangeable manner or refuse to listen to different sounds. The formulation of policies and measures often results in that a slight move in one part may affect the situation as a whole. It is vital to give an overall consideration, and plan the structure and layout. Secondly, the implementation of policy measures should be flexible to some extent, that is, it must not merely adhere to the principle but maintain flexibility as well, change with the times and make the best use of the circumstances in line with the purpose of serving students and teachers.

\section{"Unify Knowledge and Action", Promote Management Innovation}

Management innovation under the guidance of "the unity of knowledge and action" should first establish scientific standards and practical operation norms, relying on a whole set of management mechanisms and examination and evaluation systems. We emphasize "the unity of knowledge and action" in the construction of the contingent of cadres in colleges and universities, first of all, we should let the majority of cadres to understand what are the standards and what kind of action is affirmed and encouraged. It is encouraged to promote the assessment system that is diversified, in line with the school's teaching practice, and characterized by strong operability and timely feedback, make clear the assessment standards and rewards and punishment measures, and actively create an innovative management model for efficient cadres.

\section{The Steps for the Construction of the Contingent of Cadres in Colleges and Universities in the Theory of "the Unity of Knowledge and Action"}

To Strengthen the Learning of the Idea of "the Unity of Knowledge and Action" for University Cadres

The leading cadres in colleges and universities often have high cultural accomplishments and ideological consciousnesses. Therefore, in the process of advancing "the unity of knowledge and action", we must first reach a consensus on this level and make the majority of senior management cadres recognize its necessity and urgency. We should, with scientific theories as the guidance, carefully select the course teaching materials, and reasonably arrange the time and schedule for learning. In the course of learning, we can combine the research on the development trend of higher education today as well as other contents, indicate the direction for the majority of university cadres so that they will know that sth. is so and why it is so; be efficient in learning theories and management, gradually improve the ability level in school management, professional construction and other aspects step by step.

To Make Efforts to Build a Learning-Oriented Contingent of Cadres in Colleges and Universities

With the rapid development of today's society and accelerated speed and strengthened depth of knowledge update, we need to constantly explore many new fields, and management as an old and new science has deeper connotation in the new era of economic and social development. The ability 
and quality of university cadres and the requirements for era development are always in the process of endless cycles from adaptive to unadapted and then to work hard to adapt. We must arm the contingent of cadres with advanced theories, enhance the scientific knowledge level of cadres, strive to build and create a learning-oriented contingent of cadres that are diligent in thinking, good at thinking, have a wide range of knowledge and adept in planning development, which is the basic and preliminary work to strengthen the contingent of cadres in colleges and universities.

In order to train the team of leading cadres in colleges and universities, we must strengthen the learning of ideologies and theories, organize cadres to study according to the needs of building a learning-oriented political party, and organize the construction of socialism with Chinese characteristics. In addition, we must be able to arm our minds with Chinese achievements of practice and theory, guide cadres' actions and promote practice, and strive to enhance the scientific judgment and decisive handling capacity of the majority of cadres. The vast number of university cadres should strengthen their abilities of self-perfection, self-renovation and self-improvement, do well in theoretical study, correct the wrong idea of "let me learn" in the thought of the majority of university cadres in the past, and change "let me learn" into "I want to learn".

University cadres should strive to enhance their level of modern knowledge, which is not only the requirements of the times, but also the objective needs of the work of university cadres. The objects of the work of university cadres are mainly the teachers and students whose ability and knowledge level are at a relatively high level. Without a proper knowledge system as the basis, the work of university cadres will inevitably encounter all sorts of difficulties, and sometimes they are even at a loss over a particular problem. Management is a science and it requires continuous theoretical study and practice improvement. University cadres should strive to grasp the latest frontier and dynamic development of modern education, and with their posts as the basis, identify the gaps and overcome defects in practice, and seek efficiency in delicacy management and adapt to the needs of comprehensive construction and innovative development of colleges and universities.

\section{To Strengthen the Targeted Cadre Training Work}

We should do a good job in the training of university cadres, this training can be directed at a certain point or a particular problem. The cadre training work plays a quite positive role in the development of cadres and the improvement of cadres' ability, etc., and it is an effective way to broaden cadres' horizons and enhance their ideological awareness. We need to develop training systems on a regular or irregular basis and make them normalized and targeted. We should do the cadre training work in a planned way with tasks and attendance, carry out the targeted training work pursuant to the differences of personnel's posts, knowledge levels and working years and have a definite purpose in doing the work. In training, we should follow the principle of supplementing what we are lack of and learning what we need, grasp the key points and ensure the actual effect, closely combine situation needs with development needs, make constant innovations, and gradually establish an open, long-term and scientific training framework.

\section{To Establish and Improve the Scientific Cadre Appointment and Selection Mechanism}

In the appointment and selection of cadres, we must take the criteria of"the unity of knowledge and action" as the benchmark for assessing cadres, should not just listen to what the cadres say, but carefully assess how cadres do, what they do, whether they do well, and how much practical significance of what they do for the enhancement of the school's overall construction. Furthermore, we should adhere to a scientific idea of employment and development view, and the employees should have both virtue and talent, and besides, they are required to be good at learning and competent in practice. The organization department should conscientiously maintain a strict standard in the appointment and selection of cadres, adhere to giving play to democratic centralism and handle matters strictly in accordance with the provisions and rules with the implementation standards not out of shape or flexible; form a fairly good orientation of employment in colleges and universities by selecting and appointing cadres, and make those excellent cadres who forge ahead with determination and dare to take their responsibilities to stand out from the crowd; strengthen the training and cultivation of young cadres so that the majority of young cadres can do something and achieve something. 


\section{To Establish a Scientific Evaluation System}

The composition of university cadres' comprehensive competence is manifold, so how to establish a scientific, effective and strongly operational evaluation system is an urgent problem to be solved before the construction of the contingent of cadres at present. A set of effective evaluation system plays a good supervisory role for the development of cadres themselves, which constrains the thoughts and actions of the majority of cadres. The assessment of virtue and the assessment of talent have their respective characteristics. The evaluation standard cannot be rigid by taking a sweeping approach, instead, it should be comprehensive and objective, and easy to operate. The establishment and perfection of the evaluation system needs a process, and we should encourage the majority of university teachers to participate in the construction of the system to give advice and suggestions, and combine centralism and democracy together at the very beginning.

\section{Conclusions}

The idea of "the unity of knowledge and action" emphasizes to experience and observe the inner heart, make an investigation and restraint, and this moral concept is consistent with human development in the traditional Chinese Confucianism. The idea of"the unity of knowledge and action" adapts to the actual needs for the development and construction of the contingent of cadres in colleges and universities. We should, with this as the guidance, cultivate a large number of active and progressive, pioneering and innovative management talents, enhance the school's construction level and competitiveness, continue to promote the rapid, steady and healthy development of colleges and universities.

\section{References}

[1] Zhang Yanxia, Fan Jun. The Construction of the Ranks for Cadres at the Basic Level in the Institutions of Higher Learning from the Perspective of Strengthening Party Self-discipline[J]. Ideological and Political Education Research, 2017,33(03):97-100.

[2] Yue Jiguang, Jiang Jing, Sun Yechen, Zheng Jingjing. A Probe into the Ideological Construction Path of Grass-roots United Front Cadres in Colleges and Universities - Taking Tongji University as an Example[J]. Journal of Shanghai Institute of Socialism, 2017(01):46-51.

[3] Geng Jiyuan, Han Xuefeng. The Construction of University Cadres from the View of Learning Organizations[J]. Journal of Liaoning Technical University (Social Science Edition), 2014,16(04): 446-448.

[4] Sun Huihuan. The Construction of College Student Cadres from the Perspective of Team Building [J].University Student Counselor, 2014(03):34-37.

[5] Guo Qinghua. Reflections on the Team Building of Party Work Cadres in Non-governmental Institutions of Higher Learning[J]. Journal of Shenyang Institute of Engineering (Social Science Edition), 2014, 10(01): 17-20.

[6] Han Jun, Xu Bo. The Problems and Innovative Strategies of Team Building of Cadres in Colleges and Universities in the New Period [J]. Journal of Dalian University,2013,34(06):124-127.

[7] Tian Xiaoyong, Li Chang. Reflections on Strengthening the Construction of the Contingent of Party Work Cadres in Colleges and Universities in Ningxia[J]. Journal of Ningxia Normal University,2013,34(02): 131-134.

[8] Liu Xingde, Liu Zhi, Wang Chen, Jia Shuiku. Strengthen the Construction of the Contingent of Defense Cadres in Colleges and Universities in the Capital and Strive to Maintain the Safety and Stability of Campuses [J]. Studies in Ideological Education,2012(12):81-84.

[9] Wang Jian, Tang Xiaohu. Research and Practice on the Construction of the Contingent of Party Work Cadres in Non-governmental Institutions of Higher Learning [J]. Journal of Wuyi University,2012,31(01):87-90.

[10]Chen Jiefeng. Reflections on Strengthening and Improving the Construction of Discipline Inspection and Supervision Cadres in Colleges and Universities[J]. Journal of Xiangnan 
University,2010,31(06):5-7+12.

[11]Zhou Tao. On the Construction of the Contingent of High-quality Student Cadres in Colleges and Universities [J]. Reform and Opening, 2010(14):138.

[12] He Qi,Lai Fang. Research on the Construction of the Contingent of Student Cadres in Colleges and Universities - A Case Study of Guangxi Universities [J].Theory Research, 2010(03):128-130. 